\title{
Ethnic Diversity in Children's Books in the Netherlands
}

\author{
Ymke de Bruijn ${ }^{1} \cdot$ Rosanneke A. G. Emmen ${ }^{1}$ · Judi Mesman ${ }^{1,2}$
}

Published online: 15 July 2020

(c) The Author(s) 2020

\begin{abstract}
The present study examined the representation of authors, illustrators, and characters of color in books for young children (6 years old and under) that (1) have won awards, (2) were purchased most often, and (3) were borrowed most often from libraries in the Netherlands from 2009 to 2018. Factors influencing the prominence of characters were explored. In total, 64 books and 2053 characters were coded, and representation statistics were compared to statistics of the national population. Results suggest a slight underrepresentation of authors of color as compared to population statistics, and an underrepresentation of characters of color as compared to the target audience. Results on some factors influencing prominence suggest that White characters and characters of color play an equally prominent role in the books. Results on other factors, however, suggest that characters of color, especially females, are less prominent in terms of their role in the story, whether they have a name, and in relation to the number of other characters in the book. The results provide an insight in to ethnic diversity in popular books for young children in the Netherlands, and show some room for improvement in terms of representation and prominence of characters of color, so that children of color might have more opportunities to identify with characters and that readers could be exposed to ethnic diversity as represented in society.
\end{abstract}

Keywords Children's literature $\cdot$ Books for young children $\cdot$ Ethnic diversity $\cdot$ Representation

\section{Introduction}

Books specifically aimed at young children, mostly picturebooks or books containing a lot of illustrations, lend themselves perfectly for shared book reading and discussions concerning the content. The often page-filling pictures reinforce interactive story reading between parent and child (Greenhoot et al. 2014). Reading and discussing books with characters of different ethnic backgrounds can have a positive effect on children's interethnic attitudes (Cameron et al. 2006, 2007; So 2016). Previous studies from the

Electronic supplementary material The online version of this article (https://doi.org/10.1007/s10643-020-01080-2) contains supplementary material, which is available to authorized users.

Ymke de Bruijn

y.de.bruijn@luc.leidenuniv.nl

1 Leiden University College, Faculty of Governance and Global Affairs, Leiden University, Turfmarkt 99, 2511 DP The Hague, The Netherlands

2 Institute of Education and Child Studies, Faculty of Social and Behavioural Sciences, Leiden University, Wassenaarseweg 52, 2333 AK Leiden, The Netherlands
United States (US) report that characters and authors of color (in this paper referring to all ethnic backgrounds that are not classified as White/European) in children's literature are rare (e.g., Eisenberg 2002; Hughes-Hassell et al. 2009; Hughes-Hassell and Cox 2010; Koss 2015; Koss et al. 2017). Although some studies give percentages of the representation in books and the national representation in the population (e.g., Kaltenbach 2005; Koss 2015; Lee 2017), statistical comparisons are lacking, a critical step to truly make inferences about over- or underrepresentation. In addition, such studies are rarely conducted in other multicultural countries than the US, whereas the national context may be related to a different representation and portrayal of ethnic diversity in children's books. The present study examines the representation of characters and authors/illustrators of color in books for young children ( 6 years old and under) in the Netherlands as compared to population statistics, as well as the characters' prominence in the stories.

\section{Importance of Diversity in Books for Young Children}

Joint reading of books at an early age can have various benefits, such as positive effects on language development and 
reading (Duursma et al. 2008; Mol and Bus 2011). All children need characters with whom they can identify, as this may positively influence their reading motivation (Hefflin and Barksdale-Ladd 2001), and consequently the frequency with which they will read, and ultimately their reading literacy (Becker et al. 2010). The similarity-identification hypothesis implies that it is easier to identify with characters who are similar to the reader, although it remains unclear how identification works in specific contexts (Cohen et al. 2018). A basic form of similarity is based on demographic characteristics, such as age, gender, and ethnicity. Children aged 5-6 years old are already able to identify themselves based on ethnicity (Byrd 2012). Ethnically diverse characters are particularly important as children of color in the Netherlands generally show lower reading literacy (Verhoeven and Vermeer 2006). Apart from positive effects on language and reading, being able to identify with characters might also impact children's self-development (Roethler 1998), because characters can act as potential role models (Weitzman et al. 1972).

Exposure to ethnic diversity can also affect White children. Children learn from books by transferring knowledge, as demonstrated in these texts, to the real world (Ganea et al. 2008, 2011), giving books the potential to reflect cultural values and teach children about society (Weitzman et al. 1972; Barker 2010). Welch (2016, p. 369) for example argues that not presenting ethnic diversity in children's books can contribute '... to the cultivation of racial biases and stereotypes' and obstruct '... the cultivation of compassion for others'. In line with this argumentation, research has shown that children's outgroup attitudes were more positive after reading stories about an ingroup member being close friends with an outgroup member (Cameron et al. 2006, 2007). These results support the extended contact hypothesis: being exposed to examples of friendships between inand outgroup members results in more positive intergroup attitudes (Wright et al. 1997), although the effect seems to depend on the level and quality of direct contact (Belet 2018; Eller et al. 2012). In addition, other research found that reading and discussing books with a multicultural theme in an educational setting resulted in 5-year old children showing notions of human equality and positive attitudes towards other racial groups in group discussions and individually written texts (So 2016). Furthermore, courses for prospective teachers in which multicultural children's books were incorporated increased their cultural awareness (Iwai 2013) and perceived ability to teach culturally responsive (Frye et al. 2010).

Ethnic diversity in children's books can therefore not only be beneficial for identification with characters by children of color, they might also contribute to White children's, and even adults', more inclusive world views. As childhood is described as a time of learning about the world (McIntyre
2017), and interethnic prejudice already emerges at a young age (Raabe and Beelmann 2011), it is important to provide books containing ethnic diversity. Books aimed at young children, containing both visual and textual information and designed to be co-read and discussed with an adult, can be the perfect tool for this means.

\section{Previous Studies on Ethnic Diversity in Children's Books}

Numerous studies have examined the degree of ethnic diversity within children's books and among the authors and illustrators (e.g., Eisenberg 2002; Hughes-Hassell and Cox 2010; Kaltenbach 2005; Koss 2015; Koss et al. 2017; Lee 2017), and performed diversity audits on library youth collections (Mortensen 2019; Williams and Deyoe 2014). Most of the previously studied books (76-94\%) were created by White authors and illustrators (Eisenberg 2002; HughesHassell et al. 2009; Koss 2015; Koss et al. 2017). Authors and illustrators can inspire children as role models, and authors and illustrators of color may be particularly suited to create books portraying characters of color accurately (Bista 2012). Indeed, multicultural children's books were less often written by White authors (33\%) compared to other children's books (94\%; Eisenberg 2002), and almost all the authors of color had written books about their own ethnic group (Hughes-Hassell et al. 2009), but the vast majority of books containing multiple ethnic groups were written and illustrated by White authors/illustrators (Hughes-Hassell and Cox 2010).

Most of the children's books previously studied (71-90\%) contained White characters (Hughes-Hassell and Cox 2010; Kaltenbach 2005), and included at least one White protagonist or secondary character $(84 \%$; Hughes-Hassell et al. 2009). People of color were represented in $35 \%$ of the books (Hughes-Hassell and Cox 2010), and were included as a protagonist or secondary character in $26 \%$ of the books (Hughes-Hassell et al. 2009). In addition, in 60\% of the books all characters were White, while $10 \%$ of the books included only people of color (Hughes-Hassell and Cox 2010). To be able to speak of over- and underrepresentation, comparisons with population statistics are needed. Doing so, Kaltenbach (2005) reports an overrepresentation of books containing African American (31\%) and Asian characters (12\%) among the studied Caldecott books and an underrepresentation of books containing Hispanic (less than 1\%), Native American (less than 1\%) and White characters (71\%). In addition, statistics of books depicting White characters (66\%) are not that different from US population statistics (63\%, Koss 2015). However, comparisons based on the number of characters are more informative.

Studies on the protagonists in children's books have reported that the majority of these characters were White 
(70-78\%), while percentages for other ethnicities ranged from 0 to $15 \%$ (Eisenberg 2002; Koss 2015; Koss et al. 2017; Lee 2017). Comparing the representation of ethnic appearances of protagonists to the ethnic backgrounds in the target audience, in this case Texas students in grade 3-6, Lee (2017) demonstrated that while Hispanic (9\%) and African American protagonists (4\%) were underrepresented as compared to the target audience (53\% and $13 \%$ ), White protagonists $(78 \%)$ were overrepresented $(28 \%$ in the target audience). It was, however, not tested whether the statistics differed significantly.

Apart from ethnic appearance, other factors may be related to the degree to which children identify with characters in the book. Both gender and age are suggested to be important characteristics influencing the level of identification with a character (Chen et al. 2016). In earlier studies on ethnic diversity among characters, age of the characters was coded, but not analyzed in relation to ethnicity (Eisenberg 2002; Kaltenbach 2005; Koss et al. 2017). Such an association might impact how easily children can identify with characters. Similarly, although ethnicity and gender representation in children's books are sometimes researched and discussed simultaneously (Harlin and Morgan 2009; Koss 2015; Lee 2017), little research has included the intersection between the two. Intersectionality suggests that using a single-axis such as gender or ethnicity to analyze experiences is not sufficient and that the intersection and interaction between these dimensions needs to be taken into account (Crenshaw 1989). McIntyre (2017) found an association between gender and ethnicity in books that were sold most often in the US, but not in books selected by teachers. Likewise, Eisenberg (2002) did not find a significant interaction between gender and ethnicity. More research including the interaction between gender and race when examining representations in children's books is needed.

\section{Content Analysis}

Representation only, defined as merely being present, does not address the roles and prominence of the characters. Factors impacting prominence can be character-specific, such as the role characters have in the story, whether they have a name, whether they are shown on the cover of the book, on how many pages or pictures they are shown, or bookspecific, such as the number of other characters in the book. Most previous studies on the representation of characters of color in children's books have focused specifically on protagonists (Eisenberg 2002; Koss 2015; Koss et al. 2017; Lee 2017) or did not differentiate between different levels of the role of the characters (Hughes-Hassell and Cox 2010; Kaltenbach 2005). As Bishop (2013) suggests that children should be exposed to seeing characters of various ethnicities in everyday contexts, not only protagonists, but also secondary characters and even background characters are of interest. Content analyses should therefore focus on all human characters, and take factors influencing the prominence of characters into account.

\section{The Present Study}

The present study is conducted in the multicultural context of the Netherlands. In the Netherlands approximately $70 \%$ of parents with a child under the age of six read to their child every day, and $20 \%$ of the parents read to their child two or three times a week (Duursma 2014). The Dutch population consists of various cultures and ethnicities, as demonstrated by the long list of countries of birth of the Dutch population (CBS 2019a). Furthermore, 13-20\% of the population has a non-Western migration background (depending on the definition; CBS 2019b). For children aged 0-5 years, the target audience of books included in the present study, this percentages lies between 18 and 28\% (CBS 2019b). Considering the frequency of reported discrimination experiences by various traditionally underrepresented ethnic groups (Sociaal Cultureel Planbureau 2014), and the young age at which ethnic prejudice seems to emerge (Raabe and Beelmann 2011), parent-child co-reading of ethnically diverse books might be helpful in preventing interethnic prejudice in children. In the Netherlands, the Jenny Smelik/IBBY award has awarded children's books portraying ethnic/cultural diversity in a positive manner since 1983. In addition, various initiatives with a focus on increasing ethnic diversity in Dutch children's books have been set up in the last few years, such as Spinzi (2011), Zo Ook (2015), and Rose Stories (2015). There are, however, to our knowledge, no published studies on the representation of characters of color in the context of books for young children in the Netherlands.

The main aim of the present study is to examine the representation of authors, illustrators, and characters of color in books for young children (6 years old and under) in the Netherlands, similar to a diversity audit, and to compare these statistics to the Dutch population. In line with previous studies in other countries, fewer authors, illustrators, and characters of color as compared to White authors, illustrators, and characters are expected, and the authors, illustrators, and characters of color are expected to be underrepresented as compared to population statistics. The study also aims to explore other factors associated with the prominence of characters, while taking gender and age group of the characters into account. Results from the present study will provide insight into the current situation regarding ethnic diversity in books for young children in the Netherlands. These results can lead to suggestions and future directions for professionals, including authors, illustrators, and publishers, as well as customers. 


\section{Method}

\section{Materials}

When performing a content analysis on children's books, the selection of books is key. In previous research, books were often selected based on their use in schools (e.g., Eisenberg 2002; Hughes-Hassell et al. 2009), their received awards (e.g., Kaltenbach 2005; Koss et al. 2017; Lee 2017), library records (e.g., Poarch and Monk-Turner 2001) or best-seller lists (e.g., Hamilton et al. 2006). Combining sources of information will give the most complete overview of books to which children are most likely exposed.

The first step of selecting the books (see Fig. 1), therefore, was to gather all children's books published in the Netherlands that had been (1) sold most, (2) borrowed most, and (3) received an award from 2009 until 2018, without any requirements as to (the diversity of) the content. Lists with books that were sold and borrowed most often were available from the CPNB (Stichting Collectieve Propoganda van het Nederlandse Boek n.a.). Awards included in the selection process were Prentenboek van het jaar, Kinderboekwinkelprijs, Wouter Pieterse prijs, Griffels en Penselen, IBBY Honour List, Boekensleutel, Hotze de Roos Prijs, Jenny Smelik-IBBY-Prijs and Prijs van de Kinderjury. The second step was to delete all duplicates. The third step was to select books that were aimed at children of 6 years old and younger, as indicated by libraries in Amsterdam, Rotterdam and The Hague (three large cities in the Netherlands). Books labelled as AP (A Peuter, books aimed at toddlers) or AK (A Kleuter, books aimed at preschool children) were selected, as well as books from additional categories (e.g., informative books or poetry books) described as being aimed at children up to 6 years of age. If libraries used different labels, books were selected if the majority of libraries in the three cities labelled the book as described above. The fourth step was to remove books that did not contain any human figures. After coding, but prior to the analyses, six books were excluded: one book was excluded because this large-size book contained more human characters $(n=3343)$ than all other books together $(n=2128)$ and five books were excluded because all characters in the books were coded as having an unclear ethnic appearance. Lastly, five books from the same series were treated as one book (i.e., scores in terms of representation of characters were added up), as were two books from another series, resulting in a total number of 64 analyzed books (for a list of titles, see Online Appendix A).

\section{Procedure}

Coding of the selected books started with general information on the book (publisher, number of pictures, and labels of the book; for an overview of coded variables, see Online Appendix B). The label of the book could refer to a topic or genre and was based on the categorization by the Dutch libraries from which the books were borrowed (all in The Hague). Labels included were: (1) being different, (2) animals, (3) everyday life, (4) emotions, (5) family, (6) holidays/parties, (7) behavior, (8) learning, (9) body, (10) music, (11) nature, (12) on the road, (13) fairytales, (14) TVcharacters, (15) friends, (16) poetry, and (17) informative.

Fig. 1 Process of book selection

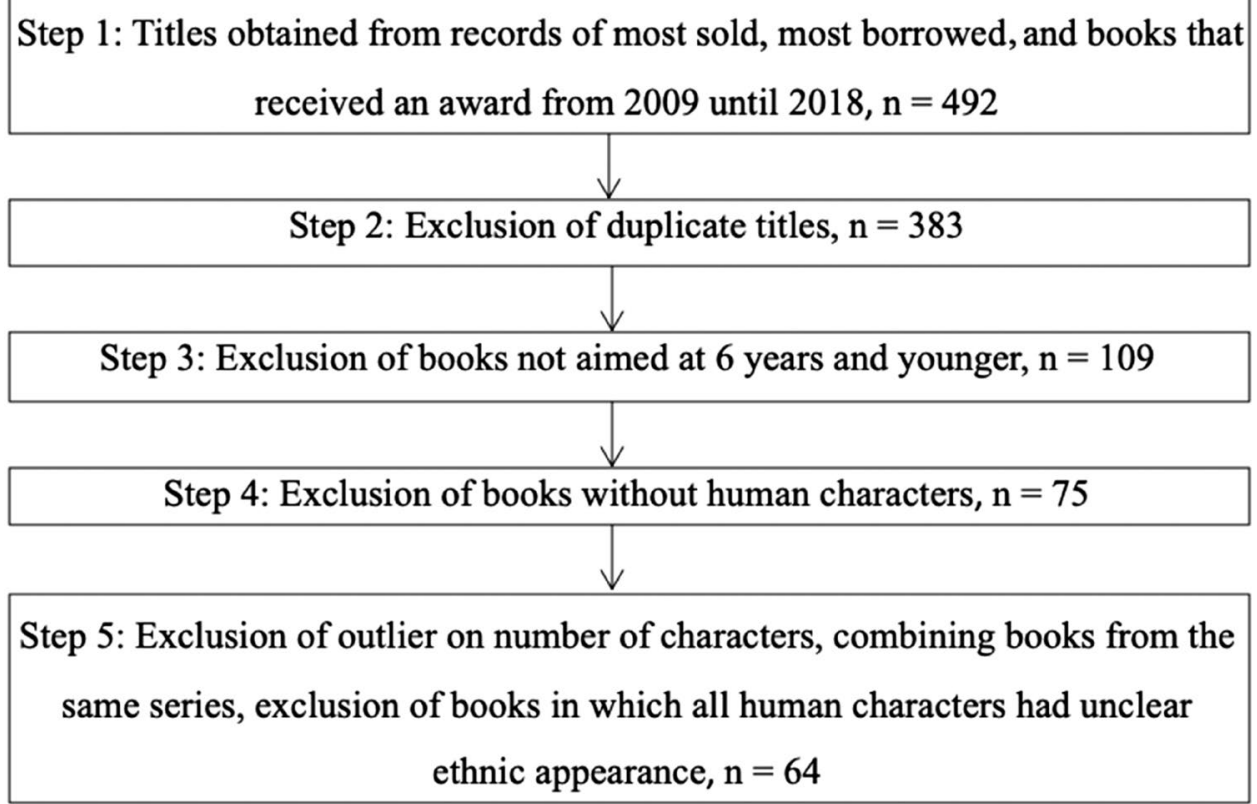


For informative books, books received an additional topic categorization. If the libraries in The Hague used different labels, the label that was used most often was selected. Next, information on the authors and illustrators was coded (ethnicity, gender), based on information that was available about them online (using a combination of information from photographs, personal webpages or Wikipedia pages). A male-female dichotomy was applied, as we did not come across any information indicating other gender identities.

Finally, all human characters displayed in the book were coded, independent of whether they were discussed in the text. Animals and other objects with human characteristics were not coded. The following was coded for each human character: name, ethnic appearance, gender, age group, role in the story, representation based on number of pictures, and representation on the cover. A White ethnic appearance was defined as not only a White skin color, but also a European ethnic appearance (e.g., Asian appearing characters could be drawn with a White skin color, but were not coded as White). Ethnic appearance was coded as of color if the ethnic appearance of a character was not (fully) perceived as White or European (e.g., had a darker skin tone and/or ethnic characteristics such as hair structure or eye shape that was not perceived as European), and could therefore be applied to characters with a wide variety of ethnic appearances. Unclear ethnic appearance was coded if the characters were drawn transparently (not using colors to distinguish the characters from the background), if the characters had a unnatural skin color (e.g., green), or if characters were drawn in such a position that ethnic features such as skin color, face, and hair could not be seen. The protagonist was defined as the most important character in the story. Multiple characters could be coded as a protagonist, for instance when the book was about a duo. Secondary characters were defined as characters who were also mentioned in the text and contributed to the story line, but not as much as the protagonist. A background character was defined as a character who was visible in the pictures, but was not mentioned in the text and did not contribute to the story. Human characters who did not contain enough detail to code two out of three main characteristics (ethnic appearance, gender, and age) were not included in the dataset. Relative representation in terms of pictures was calculated by dividing the number of pictures on which the character was presented by the total number of pictures in the book.

To assess the reliability of the coding system, two independent coders coded ten random books from the set, including 98 human characters. Interrater reliability was good for most variables ( $>0.91$ Cronbach's $\alpha$ for numeric variables and $>0.88$ Cohen's $\kappa$ for nominal variables), and lower for two character variables: 0.69 Cohen's $\kappa$ for ethnic appearance and 0.78 Cohen's $\kappa$ for representation on the cover. For this last variable, differences appeared because the coding book did not specify whether the back of the book should also be taken into account. This was therefore specified afterwards. For ethnic appearance, only 14 out of 98 characters were coded as of color, and 6 were coded as unclear. The differences in coding occurred mostly because one of the coders thought the ethnicity of the characters was not clear enough because they were drawn in the shadow. Without these 'unclear' characters, interrater reliability was 0.90 Cohen's $\kappa$. The two independent coders reached consensus scores for the ones that diverged, and clarified coding rules where necessary, after which one of the coders proceeded to code the rest of the books. Reliability between that coder's original coding and the consensus reliability set was above 0.99 (Cronbach's $\alpha$ ) for numeric variables and above 0.82 (Cohen's $\kappa$ ) for nominal variables. Books that contained a large number of characters in the background, and books with ambiguous or unclear pictures $(n=25)$ were discussed with the other coder of the reliability set. If the two coders did not reach a consensus, the books $(n=4)$ were discussed in a bigger, ethnically diverse, research team that focuses on interethnic bias and prejudice in children to reach a final coding.

\section{Population Statistics}

\section{Target Audience}

Demographics of the target audience are based on statistics about children aged $0-5$ years old in the Netherlands in 2019 (CBS 2019b). In accordance with the coding of ethnic appearance, percentages of White (Western) children and children of color (non-Western) in the population are calculated. Percentages of White (Western) children are based on the number of children with a Dutch and first or second generation Western migration background, and percentages of children of color (non-Western) are based on the number of children with a first or second generation non-Western migration background. Non-Western is defined as countries in Africa, Latin-America, Asia, and Turkey (CBS' definition, CBS n.a.), as well as Indonesia, Japan, and countries in Oceania (apart from Australia and New Zealand). Results are shown in Table 1 (G1-2 method). One could argue that

Table 1 Population statistics in The Netherlands

\begin{tabular}{lllllll}
\hline & \multicolumn{2}{l}{${\text { G1-2 } \text { method }^{\mathrm{a}}}$} & & \multicolumn{2}{l}{ G1-3 method $^{\mathrm{b}}$} \\
\cline { 2 - 3 } \cline { 6 - 7 } \cline { 5 - 6 } & Age 0-5 & General & & Age 0-5 & General \\
\hline White, Western & $81 \%$ & $84 \%$ & & $72 \%$ & $80 \%$ \\
Of color, non-Western & $19 \%$ & $16 \%$ & & $28 \%$ & $20 \%$ \\
\hline
\end{tabular}

${ }^{\mathrm{a} C h i l d r e n ~ o f ~ s e c o n d-g e n e r a t i o n ~ n o n-W e s t e r n ~ m i g r a n t s ~ a r e ~ W h i t e ~}$

${ }^{\mathrm{b}}$ Children of second-generation non-Western migrants are of color 
the percentage of children of color (non-Western) might be higher in the actual population, as some children of secondgeneration migrant parents might also be of color. Percentages are recalculated while taking third-generation backgrounds into account (CBS 2018; Table 1, G1-3 method). One could argue that this percentage of children of color (non-Western) might be lower in the actual population, as not all children of second-generation non-Western migrants might be seen as of color. Therefore, the true percentages will lie somewhere in between.

\section{General Population}

Demographics of the general population are also based on data from 2019 from CBS, without distinguishing between age groups (CBS 2019b). Again percentages of the White population and population of color are calculated in two ways, similar to the statistics of the target audience. Results are shown in Table 1.

\section{Analyses}

The final dataset consisted of 64 books and 2053 characters. Characters whose ethnic appearance was coded as unclear $(n=371)$ were excluded from analyses on the character level. After calculating descriptive statistics, the association between ethnicity of the authors and illustrators and ethnic diversity in the books was examined using Pearson Chi-Square tests. Fisher's Exact Tests are reported if the expected count in more than $20 \%$ of the cells was below five. Associations between ethnic appearance, and gender and age group of the characters were also examined using Pearson Chi-Square tests. In addition, ethnic representation among the authors, illustrators and characters was compared to population statistics using the following formulas:

$p=\frac{X 1+X 2}{n 1+n 2}$

$S E=\sqrt{p(1-p)\left(\frac{1}{n 1}+\frac{1}{n 2}\right)}$

$z=\frac{p 1-p 2}{S E}$

Furthermore, Pearson Chi-Square tests were conducted to examine the relation between ethnic appearance of the characters (White or of color) and prominence factors (role of the character, having a name, being represented on the cover). In addition, a Mann-Whitney U test was conducted to examine potential differences in representation in terms of pictures for White characters versus characters of color, as the variable was highly skewed $\left(Z_{\text {skew }}>3.29\right)$. These analyses were conducted separately per gender and per role of the character (protagonist, secondary, background). Moreover, books containing ethnic diversity (i.e. both White characters and characters of color) were compared to books without ethnic diversity in terms of number of characters using a Mann-Whitney $U$ test, as the variable again was highly skewed $\left(Z_{\text {skew }}>3.29\right)$.

\section{Results}

\section{Descriptive Statistics}

The 64 books analyzed contained 2053 characters in total, and ethnic appearance could be coded for 1757 characters. Descriptive statistics at the book level can be found in Table 2. The books were published between 2005 and 2018. Most books were published by Querido $(n=12)$, De Eenhoorn $(n=10)$, and Gottmer $(n=9)$. Most books were labelled as containing stories about emotions $(n=9)$, fairytales $(n=8)$, or as informative $(n=7)$. These informative books were about visual arts $(n=3)$, health $(n=1)$, religion $(n=1)$, fairytales and folk tales $(n=1)$, and appearance $(n=1)$.

\section{Representation}

\section{Diverse and Non-diverse Books}

In 27 books (42\%) all characters presented were White. In another 9 books (14\%), all characters presented were either White or had an unclear ethnic appearance. Further, 28 books (44\%) contained at least one human character of color, but all of these also included White characters, meaning that none of the books included only human characters of color. Most books containing both White characters and characters of color $(n=28)$ were labelled as

Table 2 Descriptive statistics at the book level $(\mathrm{N}=64)$

\begin{tabular}{lrrrr}
\hline & Min & \multicolumn{1}{c}{ Max } & \multicolumn{1}{c}{$M$} \\
\hline Year of publication & 2005 & 2018 & 2013.16 & 3.17 \\
Number of characters & 1 & 182 & 32.08 & 45.94 \\
$\begin{array}{l}\text { Number of White } \\
\quad \text { characters }\end{array}$ & 1 & 143 & 23.09 & 34.41 \\
$\begin{array}{l}\text { Number of characters } \\
\quad \text { of color }\end{array}$ & 0 & 52 & 4.36 & 9.96 \\
$\quad$ Number of pictures & 8 & 166 & 25.42 & 25.51 \\
$\quad$ Number of pages & 16 & 174 & 35.55 & 25.63 \\
$\quad$ Number of words & 0 & 16,425 & 1056.42 & 2413.94 \\
\hline
\end{tabular}


being about emotions $(n=4)$, informative topics $(n=4)$, or nature $(n=3)$. The informative books were about visual arts $(n=1)$, health $(n=1)$, religion $(n=1)$, and appearance $(n=1)$.

\section{Authors and Illustrators}

Most books $(n=59)$ were written by one author, while three books were written by two authors. Two books were wordless books, and thus no author was coded. The books were written by 49 different authors, of which $49 \%$ [95\% CI $(0.36,0.63)]$ were female and $92 \%$ [95\% CI $(0.81,0.97)]$ were White. For 26 books, the illustrations were also made by the author. Most books $(n=62)$ were illustrated by one illustrator, two books were illustrated by a duo. The books were illustrated by 52 different illustrators, of which $42 \%$ [95\% CI $(0.30,0.56)]$ were female and $90 \%$ [95\% CI $(0.79$, 0.96)] were White. Ethnicity of the author and illustrator were not significantly related to ethnic diversity in the books (see Table 3).

Comparisons between ethnic representation among authors and the general population showed that the percentage of authors of color [8\%, 95\% CI $(0.03,0.19)] \mathrm{did}$ not significantly differ from population statistics based on G1-2 method (i.e., 16\%, $z=-1.42, p=0.156$ ). However, the percentage of authors of color was significantly lower than the population percentage from G1-3 method (i.e., 20\%, $z=-2.07, p=0.038$ ). In addition, the percentage of illustrators of color $[10 \%, 95 \% \mathrm{CI}(0.04,0.21)]$ did not significantly differ from population statistics based on G1-2 method (i.e., $16 \%, z=-1.17, p=0.242$ ) or based on G1-3 method (i.e., $20 \%, z=-1.87, p=0.061$ ), although the latter comparison showed a trend towards significance.

\section{Characters}

Of the 1757 characters for whom an ethnic appearance could be coded, $84 \%$ [ $95 \%$ CI $(0.82,0.86)$ ] of the characters were White and $16 \%$ [95\% CI $(0.14,0.18)$ ] were of

Table 3 Ethnic diversity in books in relation to author and illustrator ethnicity

\begin{tabular}{llll}
\hline & $\begin{array}{l}\text { Non-diverse books } \\
(\%)\end{array}$ & $\begin{array}{l}\text { Diverse books } \\
(\%)\end{array}$ & $p$ \\
\hline Ethnicity author & & & 1.000 \\
White & 93 & 92 & \\
$\quad$ Of color & 7 & 8 & 1.000 \\
Ethnicity illustrator & & 91 & \\
White & 90 & 9 & \\
Of color & 10 & & \\
\hline
\end{tabular}

Fisher's exact test produces $\mathrm{p}$ values only
Table 4 Characteristics of White characters and characters of color

\begin{tabular}{llllll}
\hline & $\begin{array}{l}\text { White } \\
(N=1478)\end{array}$ & $\begin{array}{l}\text { Of color } \\
(N=279)\end{array}$ & $\chi$ & $d f$ & $p$ \\
\hline Gender & & & 0.20 & 2 & .906 \\
Male & $852(58 \%)$ & $164(59 \%)$ & & & \\
Female & $550(37 \%)$ & $100(36 \%)$ & & & \\
Unclear & $76(5 \%)$ & $15(5 \%)$ & & & \\
Age group & & & 2.07 & 4 & .723 \\
Child & $390(26 \%)$ & $82(29 \%)$ & & & \\
Teenager & $13(1 \%)$ & $3(1 \%)$ & & & \\
Adult & $1028(70 \%)$ & $186(67 \%)$ & & & \\
Elderly & $31(2 \%)$ & $4(1 \%)$ & & & \\
Unclear & $15(1 \%)$ & $4(1 \%)$ & & & \\
Role & & & 5.15 & 2 & .076 \\
Protagonist & $95(6 \%)$ & $14(5 \%)$ & & & \\
Secondary & $196(13 \%)$ & $25(9 \%)$ & & & \\
Background & $1187(80 \%)$ & $240(86 \%)$ & & & \\
Name & & & & & \\
Yes & $142(10 \%)$ & $19(6 \%)$ & & & \\
Rep cover & & $15(5 \%)$ & & & \\
Yes & $79(5 \%)$ & 137 & & & \\
\hline
\end{tabular}

Rep representation

color. Patterns were similar for protagonists ( 87 versus $13 \%$ ), secondary characters ( 89 versus $11 \%$ ), and background characters (83 versus 17\%). There were no significant associations between ethnic appearance of the characters and age group or gender (Table 4). For both White characters and characters of color, most of the characters were adults. In terms of gender, for both White characters and characters of color, a gap between the representation of male and female characters was found. Excluding the characters coded to have an unclear gender resulted in percentages of $61 \%$ [95\% CI $(0.59,0.63)]$ male and $39 \%$ [95\% CI $(0.37,0.41)]$ female characters. Comparing the ethnic representation of the characters to the target audience showed that the percentage of characters of color (16\%) was lower than the percentage of children of color (non-Western) in the target audience (i.e., 19\% based on G1-2 method, $z=-2.83, p=0.005,28 \%$ based on G1-3 method, $z=-11.55, p<0.001)$.

The drawings of the characters were often not detailed enough to code specific ethnicities. Most of the characters of color were described as dark skinned $(n=155)$, having a slightly darker skin tone $(n=45)$, having an East Asian appearance $(n=35)$, or having an Arab appearance $(n=29)$. When the description 'having a slightly darker skin tone' was used, it was not clear what specific ethnicity the characters were (e.g., Arab, Latin American, bicultural), but they were perceived as not being White. In some cases, it was possible to give a more specific description 
based on the context given in the pictures. These descriptions included a Native American $(n=1)$, a Latin American $(n=3)$, a South Asian $(n=3)$, a Hawaiian $(n=1)$, and an Inuit appearance $(n=7)$.

\section{Prominence}

\section{Overall Analyses}

Results of Pearson Chi square tests to examine the association between ethnic appearance and prominence factors are presented in Table 4. No significant associations were found between ethnic appearance and role of the character, having a name, and representation on the cover. A Mann-Whitney U test indicated that the relative representation (representation on number of pictures relative to total number of pictures in the book) was significantly higher for characters of color $(M d n=0.07)$ than for White characters $(M d n=0.05, U=190,319.50, p=0.039)$. Furthermore, another Mann-Whitney U test revealed that books containing ethnic diversity had significantly more characters $(M d n=30)$ than books without ethnic diversity $(M d n=4$; $U=139.00, p<0.001)$.

\section{Gender Analyses}

Male and female characters were also analyzed separately. Results of Pearson Chi square tests showed no significant associations between ethnic appearance and having a name, or being represented on the cover for males and females separately. For role of the character, there was no significant association with ethnic appearance for males, but there was for females $\left[\chi^{2}(2, N=650)=6.33, p=0.042\right]$. Female characters of color were more likely to be background characters $(90 \%)$ than White female characters $\left[79 \%, \chi^{2}(1\right.$, $N=650)=5.45, p=0.020$, OR 2.22, 95\% CI $(1.12,4.42)]$. In addition, A Mann-Whitney U test showed no significant difference in relative representation on pictures between White males or females and males or females of color.

\section{Analyses Per Role of the Character}

Similar tests were conducted for protagonists, secondary, and background characters separately. Results of Pearson Chi square tests showed no significant associations between ethnic appearance and representation on the cover for the different types of roles. Although there were no significant associations between ethnic appearance and having a name for secondary and background characters, there was for protagonists $\left[\chi^{2}(1, N=109)=4.89, p=0.027\right.$, OR $0.27,95 \%$ CI $(0.08,0.91)]$. Protagonists of color were less likely to have a name (29\%) than White protagonists (60\%). In addition, while Mann-Whitney U tests showed no significant differences between protagonist and secondary White characters and characters of color, the relative representation in terms of pictures was significantly higher for background characters of color $(M d n=0.07)$ than for White background characters $(M d n=0.05, U=116,209.50, p<0.001)$.

\section{Discussion}

The present study aimed to provide more insight in the ethnic diversity of characters, authors, and illustrators of books for young children (6 years old or under) in the Netherlands that (1) have won awards, (2) were purchased most often, and (3) were borrowed most often from libraries in the Netherlands from 2009 to 2018. Following multiple studies in the US, the present study sheds light on books to which children are likely to be exposed in another multicultural national context. Results do not suggest a strong underrepresentation of authors and illustrators of color as compared to population statistics. In contrast, as compared to the target audience (i.e., young children in the Dutch population), characters of color are more clearly underrepresented. In terms of factors influencing prominence, some contrasts suggest that White characters and characters of color play an equally prominent role in the book. Other contrasts, however, indicate less prominence of characters of color, especially females, in terms of their role in the story, whether they have a name, and the number of other characters in the book.

Results of the present study reveal that $8 \%$ of the authors and $10 \%$ of the illustrators are of color, as expected, based on previous studies reporting higher percentages of White authors and illustrators (Eisenberg 2002; Hughes-Hassell et al. 2009; Koss 2015; Koss et al. 2017). These percentages show an underrepresentation of authors and illustrators of color to some extent (only in comparison to the population when taking third generation backgrounds into account, and for illustrators the result only showed a trend towards significance), and are thus less extreme than expected. There was no association between ethnicity of the authors/illustrators and the presence of characters of color in books. Previous studies suggested that especially books featuring one ethnic group of color were more often created by professionals of color (Hughes-Hassell et al. 2009; Hughes-Hassell and Cox 2010). The set for analysis in this study, however, did not include any books that featured characters of color only. Future research will need to replicate these results in larger samples. Professionals of color might be in a specifically good position to create books about characters of color in a culturally authentic manner (Bista 2012), without stereotypes, and depicting accurate cultural values and details (Yoo-Lee et al. 2014). 
In addition, the majority of the characters were White $(84 \%)$, as expected, based on previous studies reporting lower numbers of characters of color than White characters (Eisenberg 2002; Hughes-Hassell and Cox 2010; Kaltenbach 2005; Koss 2015; Koss et al. 2017; Lee 2017). The gap between White characters and characters of color was largest for protagonists and secondary characters, and smaller for background characters. In line with previous research (Lee 2017), comparisons with the target audience (aged 0-5 years old; $19-28 \%$ of color), show an underrepresentation of characters of color (16\%). Kaltenbach (2005), in contrast, found an overrepresentation of books containing African American and Asian characters and an underrepresentation of books containing White characters. This study focused on numbers of books and not numbers of characters within those books, and results are therefore not directly comparable.

Results from the present study suggest that children of color in the Netherlands have less opportunities to be exposed to characters more similar to them in terms of ethnic appearance than White children, which might have an impact on their reading motivation and self-development (Hefflin and Barksdale-Ladd 2001; Roethler 1998). As the degree of ethnic diversity in books for young children in the Netherlands is lower than in society, they do not seem to use their full potential in terms of teaching children about society (Weitzman et al. 1972; Barker 2010), and providing pathways to more positive intergroup attitudes (Cameron et al. 2006, 2007; So 2016). To establish these effects, however, merely the representation of characters of color in books for young children might not be sufficient, but examples of friendships between in- and outgroup members (Cameron et al. 2006, 2007) or a multicultural theme (Frye et al. 2010; Iwai 2013; So 2016) might be needed. However, it is safe to say that when fewer characters of color are represented, chances are smaller that books contain examples of extended contact or focus on a multicultural theme inviting (co-)readers to start discussions.

Gender and age were explored as other identity salient factors in the present study (Chen et al. 2016). No age or gender differences between White characters and characters of color were found, suggesting that based on the similarityidentification hypothesis (Cohen et al. 2018), it is not more difficult for children to identify with either White characters or characters of color in the studied books based on the characters' gender or age. These results are line with previous studies reporting no significant interaction between gender and ethnicity (Eisenberg 2002; McIntyre 2017). Methods of book selection seem to make a difference, as McIntyre (2017) reports no association in books selected by teachers, but a significant association in books selected based on sale numbers. Although gender representation and gender stereotypes are beyond the scope of the present study, it is important to note that the results do show a clear underrepresentation of female characters (39\%). These findings are in line with earlier studies on gender representation among protagonists in children's books (e.g., Hamilton et al. 2006; Koss 2015), and highlight the need for diversity in children's books beyond ethnicity. Among authors and illustrators in this study, on the contrary, an approximately equal gender distribution is found, suggesting that both boys and girls have role models in these professions to look up to.

In addition, the present study showed that ethnic appearance of the characters was not related to being represented on the cover, but protagonists of color were less likely to have a name than White protagonists. In contrast, characters of color were represented on a relatively higher number of pictures than White characters. This difference, however, was only found for background characters in the books, who do not play a meaningful role in the story. Furthermore, ethnic appearance was not related to role of the characters in general, but an association was found for the female characters: female characters of color were more likely to be background characters than expected. These results highlight the need for intersectionality in studies focusing on race (Crenshaw 1989), as especially female characters of color seem to be devalued in terms of the role they play.

Secondly, factors influencing the prominence of characters can be book-specific, such as the number of other characters surrounding them. While $42 \%$ of the books contained only White characters, there were no books containing only characters of color. The results show that ethnically diverse books included more human characters than books without diversity. Characters in diverse books, the only books in which characters of color are included, will therefore generally play a less prominent role based on the number of other characters surrounding them than characters in non-diverse books. Although not all comparisons on prominence factors revealed unfavorable results for characters of color, the significant contrasts show that there is room to improve the prominence of characters of color.

Several limitations of this study should be noted. Firstly, the two coders of the present study were both White. Although the coders consulted a bigger, ethnically diverse, research team if they did not reach a consensus, bias based on experience with and exposure to other groups (i.e., their propriospect) might be present in codings on which they agreed (Hughes-Hassell et al. 2009; Wolcott 1991). Secondly, the ethnicity of the characters is based on drawings, because explicit mentions of ethnicity, cultural background or nationality were scarce (only $1 \%$ of the cases). Drawings are often not very detailed, making it difficult to determine specific ethnic or cultural backgrounds, so that the characters could only be analyzed in general terms of White and of color (or unclear). More specific information on the representation of various ethnic groups of color would provide an even clearer picture of ethnic diversity in books for young children. 
Future research will need to more closely examine the ways in which characters are portrayed. Although the present study has already looked beyond the mere numbers of representation and examined aspects promoting prominence, a qualitative examination of the characters would provide insight in the quality of the representation and their cultural authenticity (Yoo-Lee et al. 2014). A qualitative approach could also examine the messages that are conveyed in the books and the role that culture or ethnicity plays. This information could be used to identify the nature of books including ethnic diversity: socially conscious books (those that deal with racial conflicts), melting pot books (those that do not emphasize any cultural issues or contexts), or culturally conscious books (those that do pay attention to cultural contexts; Bishop 2012).

The present study adds to existing literature by examining books for young children (6 years old and under) in the Netherlands, by using multiple sources of information in the book selection process, and by focusing not only on numbers of representation but also on factors influencing prominence. Results from the present study suggest that there is a slight underrepresentation of authors of color, and room for improvement in terms of representation and prominence of characters of color, especially females, in books for young children in the Netherlands. Improvements will provide more opportunities for children of color to identify with characters and for White children to get familiar with ethnic diversity as also represented in society. Professionals such as publishers, authors and illustrators, as well as consumers, such as parents and other co-readers, should be aware of the current situation regarding ethnic diversity and take this information into account whenever deciding to publish, write, illustrate, or read a new book.

Funding This research did not receive any specific grant from funding agencies in the public, commercial, or not-for-profit sectors.

\section{Compliance with Ethical Standards}

\section{Conflict of interest There are no conflicts of interest.}

Open Access This article is licensed under a Creative Commons Attribution 4.0 International License, which permits use, sharing, adaptation, distribution and reproduction in any medium or format, as long as you give appropriate credit to the original author(s) and the source, provide a link to the Creative Commons licence, and indicate if changes were made. The images or other third party material in this article are included in the article's Creative Commons licence, unless indicated otherwise in a credit line to the material. If material is not included in the article's Creative Commons licence and your intended use is not permitted by statutory regulation or exceeds the permitted use, you will need to obtain permission directly from the copyright holder. To view a copy of this licence, visit http://creativecommons.org/licenses/by/4.0/.

\section{References}

Barker, J. L. (2010). Racial identification and audience in roll of thunder, hear my cry and the Watsons go to Birmingham-1963. Children's Literature in Education, 41, 118-145. https://doi. org/10.1007/s10583-01-9101-4.

Becker, M., McElvany, N., \& Kortenbruck, M. (2010). Intrinsic and extrinsic reading motivation as predictors of reading literacy: A longitudinal study. Journal of Educational Psychology, 102, 773-785. https://doi.org/10.1037/a0020084.

Belet, M. (2018). Reducing interethnic bias through real-life and literary encounters: The interplay between face-to-face and vicarious contact in high school classrooms. International Journal of Intercultural Relations, 63, 53-67. https://doi.org/10.1016/j. ijintrel.2018.01.003.

Bishop, K. (2013). Making multicultural literature meaningful. Knowledge Quest, 32(1), 27-28.

Bishop, R. S. (2012). Reflections on the development of African American children's literature. Journal of Children's Literature, $38(2), 5-13$.

Bista, K. (2012). Multicultural literature for children and young adults. The Educational Forum, 76(3), 317-325. https://doi. org/10.1080/00131725.2012.682203.

Byrd, C. M. (2012). The measurement of racial/ethnic identity in children: A critical review. Journal of Black Psychology, 38(1), 3-31. https://doi.org/10.1177/0095798410397544.

Cameron, L., Rutland, A., \& Brown, R. (2007). Promoting children's positive intergroup attitudes towards stigmatized groups: Extended contact and multiple classification skills training. International Journal of Behavioral Development, 31(5), 454-466. https://doi.org/10.1177/0165025407081474.

Cameron, L., Rutland, A., Brown, R., \& Douche, R. (2006). Changing children's intergroup attitudes toward refugees: Testing different models of extended contact. Child Development, 77(5), 1208-1219. https://doi.org/10.1111/j.1467-8624.2006.00929.x.

CBS (2018). Kinderen van tweede generatie ouders, 1 januari 2018. Retrieved 21 November 2019 https://www.cbs.nl/nl-nl/maatw erk/2018/47/kinderen-van-tweede-generatie-ouders-1-janua ri-2018.

CBS (2019a). Bevolking op 1 januari; leeftijd, geboorteland en regio. Retrieved 21 November 2019 http://statline.cbs.nl/Statweb/publi cation $/ ? \mathrm{DM}=\mathrm{SLNL} \& \mathrm{PA}=70648 \mathrm{ned} \& \mathrm{D} 1=0 \& \mathrm{D} 2=\mathrm{a} \& \mathrm{D} 3=\mathrm{a} \& \mathrm{D}$ $4=0 \& \mathrm{D} 5=1 \& \mathrm{HDR}=\mathrm{T}, \mathrm{G} 3, \mathrm{G} 4 \& \mathrm{STB}=\mathrm{G} 2, \mathrm{G} 1 \& \mathrm{VW}=\mathrm{T}$.

CBS (2019b). Bevolking; generatie, geslacht, leeftijd en migratieachtergrond, 1 januari. Retrieved 21 November 2019 https ://opendata.cbs.nl/statline/\#/CBS/nl/datas et/37325/table $? \mathrm{ts}=1539777137624$.

CBS (n.a.). Wat is het verschil tussen een Westerse en niet-Westerse allochtoon? Retrevied 21 November 2019 https://www.cbs.nl/ nl-nl/faq/specifiek/wat-is-het-verschil-tussen-een-westerse-enniet-westerse-allochtoon.

Chen, M., Bell, R. A., \& Taylor, L. D. (2016). Narrator point of view and persuasion in health narratives: The role of protagonistreader similarity, identification, and self-referencing. Journal of Health Communication, 21(8), 908-918. https://doi. org/10.1080/10810730.2016.1177147.

Cohen, J., Weimann-Saks, D., \& Mazor-Tregerman, M. (2018). Does character similarity increase identification and persuasion? Media Psychology, 21(3), 506-528. https://doi. org/10.1080/15213269.2017.1302344.

Crenshaw, K. (1989). Demarginalizing the intersection of race and sex: A Black feminist critique of antidiscrimination doctrine, feminist theory, and antiracist politics. University of Chicago Legal Forum, pp. 139-167. 
Duursma, E. (2014). Parental bookreading practices among families in the Netherlands. Journal of Early Childhood Literacy, 14(4), 435-458. https://doi.org/10.1177/1468798414523025.

Duursma, E., Augustyn, M., \& Zuckerman, B. (2008). Reading aloud to children: The evidence. Archives of Disease in Childhood, 93(7), 544-557.

Eisenberg, K. N. (2002). Gender and ethnicity stereotypes in children's books (Doctoral dissertation). Retrieved 16 October 2018 https://search-proquest-com.ezproxy.leidenuniv.nl:2443/docvi ew/251657696? pq-origsite $=$ primo.

Eller, A., Abrams, D., \& Gomez, A. (2012). When the direct route is blocked: The extended contact pathway to improving intergroup relations. International Journal of Intercultural Relations, 36(5), 637-646. https://doi.org/10.1016/j.ijintrel.2012.03.005.

Frye, B., Button, L., Kelly, C., \& Button, G. (2010). Preservice teachers' self-perceptions and attitudes toward culturally responsive teaching. Journal of Praxis in Multicultural Education, 5(1), 5. https://doi.org/10.9741/2161-2978.1029.

Ganea, P. A., Ma, J., \& DeLoache, J. S. (2011). Young children's learning and transfer of biological information from picture books to real animals. Child Development, 82(5), 1421-1433. https://doi. org/10.1111/j.1467-8624.2011.01612.x.

Ganea, P. A., Pickard, M. B., \& DeLoache, J. S. (2008). Transfer between picture books and the real world by very young children. Journal of Cognition and Development, 9(1), 46-66. https://doi. org/10.1080/15248370701836592.

Greenhoot, A. F., Beyer, A. M., \& Curtis, J. (2014). More than pretty pictures? How illustrations affect parent-child story reading and children's story recall. Frontiers in Psychology, 5, 738. https://doi. org/10.3389/fpsyg.2014.00738.

Hamilton, M. C., Anderson, D., Broaddus, M., \& Young, K. (2006). Gender stereotyping and under-representation of female characters in 200 popular children's picture books: A twenty-first century update. Sex Roles, 55(11/12), 757-765. https://doi.org/10.1007/ s11199-006-9128-6.

Harlin, R., \& Morgan, H. (2009). Review of research: Gender, racial and ethnic misrepresentation in children's books: A comparative look. Childhood Education, 85(3), 187-190. https://doi. org/10.1080/00094056.2009.10521389.

Hefflin, B. R., \& Barksdale-Ladd, M. A. (2001). African American children's literature that helps students find themselves: Selection guidelines for grades K-3. The Reading Teacher, 54(8), 810-819.

Hughes-Hassell, S., Barkley, H. A., \& Koehler, E. (2009). Promoting equity in children's literacy instruction: Using a critical race theory framework to examine transitional books. School Library Media Research, 12, 1-20.

Hughes-Hassell, S., \& Cox, E. J. (2010). Inside board books: Representations of people of color. The Library Quarterly, 80(3), 211-230. https://doi.org/10.1086/652873.

Iwai, Y. (2013). Multicultural children's literature and teacher candidates' awareness and attitudes toward cultural diversity. International Electronic Journal of Elementary Education, 5(2), 185-198.

Kaltenbach, S. L. (2005). The multicultural aspects of the Caldecott and honor books (Doctoral dissertation). Retrieved 16 October 2018 https://etd.ohiolink.edu/rws_etd/document/get/bgsu112058 2732/inline.

Koss, M. D. (2015). Diversity in contemporary picturebooks: A content analysis. Journal of Children's Literature, 41(1), 32-42.

Koss, M. D., Martinez, M. G., \& Johnson, N. J. (2017). Where are The Latinx? Diversity in Caldecott Winner and Honor Books. Bilingual Review, 33(5), 50-62.

Lee, E. L. (2017). Exploring diversity representation in literature for children: A content analysis of the 2015-16 Texas Bluebonnet
Award Master List (Doctoral dissertation). Retrieved 16 October 2018 https://uh-ir.tdl.org/uhir/bitstream/handle/10657/1882/LEEDISSERTATION-2017.pdf? sequence $=1$ \&isAllowed $=\mathrm{y}$.

McIntyre, J. (2017). Gender and race in children's picture books: A tragedy in three studies (Doctoral dissertation). Retrieved 19 June 2019 https://dash.harvard.edu/bitstream/handle/1/33052849/ MCINTYRE-DISSERTATION-2017.pdf?sequence $=1 \&$ isAll owed $=\mathrm{y}$.

Mol, S. E., \& Bus, A. G. (2011). To read or not to read: A meta-analysis of print exposure from infancy to early adulthood. Psychological Bulletin, 137(2), 267-296. https://doi.org/10.1037/a0021890.

Mortensen, A. (2019). Measuring diversity in the collection. Library Journal, 144(4), 28-30.

Poarch, R., \& Monk-Turner, E. (2001). Gender roles in children's literature: A review of non-award winning "easy-to-read" books. Journal of Research in Childhood Education, 16(1), 70-76. https ://doi.org/10.1080/02568540109594975.

Raabe, T., \& Beelmann, A. (2011). Development of ethnic, racial, and national prejudice in childhood and adolescence: A multinational meta-analysis of age differences. Child Development, 82, 17151737. https://doi.org/10.1111/j.1467-8624.2011.01668.x.

Roethler, J. (1998). Reading in color: Children's book illustrations and identity formation for Black children in the United States. African American Review, 32(1), 95-105. https://doi.org/10.2307/30422 72.

So, J. K. (2016). Opening up spaces for early critical literacy: Korean kindergarteners exploring diversity through multicultural picture books. Australian Journal of Language and Literacy, 39(2), 176-187.

Sociaal Cultureel Planbureau. (2014). Ervaren discriminatie in Nederland. Den Haag: SCP.

Stichting Collectieve Propoganda van het Nederlandse Boek. (n.a.). CPNB Top 100 Archief.https://www.cpnb.nl/campagnes/cpnbtop-100-2018/uitgaven. Accessed 14 June 2019.

Verhoeven, L., \& Vermeer, A. (2006). Sociocultural variation in literacy achievement. British Journal of Educational Studies, 54(2), 189-211. https://doi.org/10.1111/j.1467-8527.2006.00341.x.

Weitzman, L. J., Eifler, D., Hokada, E., \& Ross, C. (1972). Sex-role socialization in picture books for preschool children. American Journal of Sociology, 77(6), 1125-1150.

Welch, B. F. (2016). The pervasive whiteness of children's literature: Collective harms and consumer obligations. Social Theory and Practice, 42(2), 367-388. https://doi.org/10.5840/soctheorpract20 1642220.

Williams, V. K., \& Deyoe, N. (2014). Diverse population, diverse collection? Youth collections in the United States. Technical Services Quarterly, 31(2), 97-121.

Wolcott, H. F. (1991). Propriospect and the acquisition of culture. Anthropology \& Education Quarterly, 22(3), 251-273.

Wright, S. C., Aron, A., McLaughlin-Volpe, T., \& Ropp, S. A. (1997). The extended contact effect: Knowledge of cross-group friendships and prejudice. Journal of Personality and Social Psychology, 73(1), 73-90.

Yoo-Lee, E., Fowler, L., Adkins, D., Kim, K. S., \& Davis, H. N. (2014). Evaluating cultural authenticity in multicultural picture books: A collaborative analysis for diversity education. The Library Quarterly, 84(3), 324-347.

Publisher's Note Springer Nature remains neutral with regard to jurisdictional claims in published maps and institutional affiliations. 